\title{
A highly efficient separation and physicochemical characteristics of saturated fatty acids from crude palm oil fatty acids mixture using methanol crystallisation method
}

\author{
Abd Al-Wali Japir ${ }^{1}$, Jumat Salimon ${ }^{1}$, Darfizzi Derawi ${ }^{1}$, Badrul Hisham Yahaya ${ }^{2}$, Murad Bahadi ${ }^{1}$, \\ Salah Al-Shuja'a ${ }^{3}$ and Muhammad Rahimi Yusop ${ }^{1,2, *}$ \\ ${ }^{1}$ School of Chemical Sciences and Food Technology, Faculty of Science and Technology, Universiti Kebangsaan Malaysia, 43600 Bangi, \\ Selangor, Malaysia \\ ${ }^{2}$ Kluster Perubatan Regeneratif, Institut Perubatan dan Pergigian Termaju, Universiti Sains Malaysia, 13200 Bertam Kepala Batas, Pulau \\ Pinang, Malaysia \\ ${ }^{3}$ School of Chemical Engineering and Technology, Tianjin University, 135, Yaguan Road, Jinnan District, 300350 Tianjin, PR China
}

Received 16 September 2017 - Accepted 2 January 2018

\begin{abstract}
The objective of the current study was to separate saturated fatty acids (SFAs) from high free fatty acid crude palm oil fatty acid mixture using the methanol crystallisation method. The development of methanol crystallisation method procedure was based on various parameters. The fatty acid composition was determined by using gas chromatography-flame ionisation detector (GC-FID) as Fatty Acid Methyl Esters. The highest percentage of SFAs was more than $89 \%$ with the percentage yield of $48.9 \%$ under the optimal conditions of the fatty acids-to-methanol ratio of 1:15 (w/v), the crystallisation temperature of $-15^{\circ} \mathrm{C}$, and the crystallisation time of 24 hours, respectively. After a double crystallisation, the composition of separated SFAs contains $90 \%$ of palmitic acid $\left(\mathrm{C}_{16: 0}\right)$ as a major component and $5.8 \%$ of stearic acid $\left(\mathrm{C}_{18: 0}\right)$, respectively. Moreover, almost $4.2 \%$ of oleic acid $\left(\mathrm{C}_{18: 1}\right)$ was observed in the saturated solid product. Based on the results, the use of methanol as a crystallisation solvent is recommended because of its high efficiency, low cost, stability, obtainability, and comparative ease of recovery.
\end{abstract}

Keywords: high free fatty acid crude palm oil / saturated fatty acids / palmitic acid / methanol crystallisation

\begin{abstract}
Résumé - Une haute efficacité de séparation et caractéristiques physico-chimique des acides gras saturés à partir d'un mélange d'huile de palme et acides gras,en utilisant la méthode de cristallisation par méthanol. L'objectif de cette étude était de séparer l'acides gras saturés provenant du mélange huile de palme et acides gras, en utilisant la méthode de cristallisation par méthanol. La procédure de développement de la méthode de cristallisation par méthanol dépend de plusieurs paramètres. La composition de l'acide gras est déterminée par la chromatographie à gaz et par détecteur de flame d'ionisation (GC-FID), sous la forme de méthyle esters d'acide gras. Le haut pourcentage de l'acide gras saturés est de $89 \%$ avec un rapport $48,9 \%$ sous la condition optimale de l'acide gras/méthanol ratio de $1 / 15$ (poids/volume). La température et le temps de cristallisation sont respectivement de $-15^{\circ} \mathrm{C}$ et $24 \mathrm{~h}$. Après une double cristallisation, la composition de l'acide gras saturés (SFAs) contient $90 \%$ de l'acide palmic (C16:0) composé majeur et $5,8 \%$ de l'acide stéarique (C18:0), également une portion de 4,2\% de l'acide oleifique a été observée dans le produit solide saturé. En se basant sur les résultats, l'utilisation de méthanol comme solvant de cristallisation est recommandable parce qu'il est hautement efficace, moins cher, stable, disponible et une facilité comparative de récupération.
\end{abstract}

Mots clés : haute disponibilité de l'acide gras / l'huile de palme brute / acides gras saturés / acide palmic / cristallisation par méthanol

\footnotetext{
*Correspondence: rahimi@ukm.edu.my
} 


\section{Introduction}

The animal fat and vegetable oils can be hydrolysed into a mixture of fatty acids. The composition of fatty acids is known for each kind of fat and oil. It consists of less than $50 \%$ unsaturated fatty acids in the animal fats (e.g., tallow) (Dogan and Temur, 2013), while some unsaturated vegetable oils, such as olive oil and sunflower contain more than $50 \%$ unsaturated fatty acids (Kostik et al., 2013). It is essential to separate SFAs from unsaturated fatty acids (USFAs). The principle of separating of saturated and unsaturated fatty acids alkyl esters mixture into two fractions using solvent crystallisation (Strohmeier et al., 2014).

It has been reported a significant commercial technique for separating the fatty acids by a selective solvent which is called "Emersol Process" (Wanasundara et al., 2005). It is established on the principles of fractional crystallisation of fatty acids from solvents at low temperatures. The emersol process involves the controlled crystallisation of fatty acids from a methanol to achieve a separation of fatty acids mixture. Fatty acids are accurately dissolved in aqueous $95 \%$ methanol. This solution is then passed among a series of pre-coolers and coolers/ crystallizers, which are maintained at temperatures, lower than freezing $\left(<-15^{\circ} \mathrm{C}\right)$. The separation of fatty acids by means of fractional crystallisation from solvents is a vital process for preparing pure fatty acids or a partially separated mixture of fatty acids. This process requires the simplest equipment and smallest number of unit operations. Briefly, the process is carried out following these steps: cooling of the oil or fatty acids mixture in a solvent and then, holding for a particular period of time and separating the crystallised fraction by filtration (Wanasundara, 2010). The solution temperature should be gradually decreased to the crystallisation temperature $(1-6 \mathrm{~h})$ and maintained in this state for 4-24 h (Wanasundara et al., 2005). Kistler et al. (1946) studied the factors necessary to select the solvent of crystallisation for separating fatty acids and finally the selection was $90 \%$ methanol because of its low cost, stability, availability, and comparative ease of recovering. All these factors were stated as justification of selection of $90 \%$ methanol and proved it more feasible than $85 \%$ acetone, $95 \%$ ethanol, petroleum ether and propylene dichloride.

Several methods used for the separation of fatty acids have been reported with varied yields, such as adsorption chromatography (Maddikeri et al., 2012), enzymatic splitting (Kempers et al., 2013), molecular distillation (Cermak et al., 2012), low-temperature crystallisation (Brown and Kolb, 1955), urea complexation (Salimon et al., 2012), and fractional crystallisation from solvents (Strohmeier et al., 2014). However, the simplest and most efficient separation for obtaining SFAs concentrates as free fatty acids are fractional crystallisation from solvents. This is a well-known technique used for the purpose of removing monounsaturated and polyunsaturated fatty acids and SFAs such as lauric acid and myristic acid that are involved in the composition of palm fatty acids mixture. Fractional crystallisation of solvents is characterised by its low cost and ability to recycle the solvent. Therefore, in this study, methanol crystallisation of a mixture of fatty acids of high free fatty acid crude palm oil was carried out to obtain concentrated SFAs and high yield. The effects of the FAs-to-methanol ratio $\left(X_{1}\right)$, crystallisation temperature
$\left(X_{2}\right)$ and crystallisation time $\left(X_{3}\right)$ were systematically studied and the factor for optimal separation was selected.

\section{Materials and method}

\subsection{Materials}

Crude palm oil was provided by Sime Darby Company, Carey Island, and Selangor - Malaysia. Fatty acid methyl esters (standard) were purchased from Sigma-Aldrich Chemical Co. Inc (St. Louis, MO, USA). Methanol and other chemical reagents used in this study were also treated with analytical grade and used without further purification.

\subsection{Preparation of free fatty acids (FFAs)}

In brief, $25 \mathrm{~g}$ of high free fatty acid crude palm oil was placed in the flask with $150 \mathrm{~mL}$ of hydrolysis solution, which contains ethanolic potassium hydroxide $(1.75 \mathrm{M})$, and ethanol $(150 \mathrm{~mL}: 90 \% \mathrm{v} / \mathrm{v})$. The hydrolysis reaction was performed in a $250 \mathrm{~mL}$ two-neck round-bottom flask at a reaction temperature of $70^{\circ} \mathrm{C}$ and reaction time $2 \mathrm{~h}$. Afterwards, the hydrolysis was done, and unsaponifiable matters were separated by adding $100 \mathrm{~mL}$ of water with $50 \mathrm{~mL}$ of hexane to the mixture. The soap containing the aqueous alcohol phase was acidified by adding $\mathrm{HCl} 6 \mathrm{~N}(\sim 60 \mathrm{~mL})$ to $\mathrm{pH}=1$ and recovered of free fatty acids by extraction with a nonpolar solvent as hexane. In addition, about $(3 \times 25 \mathrm{~mL})$ of distilled water was used to wash the extracted fatty acids mixture to neutral $\mathrm{pH}$. A separating funnel was also used to remove the resulting lower layer and discarded. Then, the upper organic layer containing FFAs was dried with anhydrous sodium sulphate, and hexane was evaporated under reduced pressure using a vacuum rotary evaporator at $35^{\circ} \mathrm{C}$ (Salimon et al., 2011). After that, free fatty acids percentage (\%FFAs) was determined.

\subsection{Determination of $\%$ FFAs}

The acidity of oil was estimated by AOCS Method Ca 5a40 (1990) (Prasanth Kumar and Gopala Krishna, 2015). To perform this, first, $0.5 \mathrm{~g}$ of FFAs was placed in a dried conical flask containing $50 \mathrm{~mL}$ of isopropanol, which was previously neutralised by an addition of sodium hydroxide $(\mathrm{NaOH}$, $0.02 \mathrm{~N}$ ). Then, $0.5 \mathrm{~mL}$ of $1 \%$ phenolphthalein indicator was added to the mixture. The flask was subsequently positioned on a hot plate and heated until the temperature reached $40^{\circ} \mathrm{C}$. After that, the mixture was titrated with a sodium hydroxide solution $(0.1 \mathrm{~N})$ until a pink colour emerged for at least 30 seconds. The percentage of FFAs was determined using equation (1).

$$
\begin{aligned}
& \% \text { FFAs as palmitic acid } \\
& =\left[\frac{(\mathrm{mL} \text { of titrant } \times(\mathrm{N}) \text { of titrant }) \times(25.6)}{(\mathrm{W})}\right]\left(\frac{\mathrm{mg} \mathrm{NaOH}}{\mathrm{g} \text { sample }}\right),
\end{aligned}
$$

where, $\mathrm{mL}$ is volume of $\mathrm{NaOH}$ solution used; $\mathrm{N}$ is normality of $\mathrm{NaOH}$ solution; W is weight of sample in grams. 


\subsection{Methanol crystallization}

The crystallisation of palm fatty acids mixture (PFAM) was carried out with a proper beaker in a refrigerator provider to control the temperature. The fatty acid mixture was crystallised from aqueous methanol (95\%). The fatty acid: methanol ratios were varied from 1:5 (g:mL) - 1:25 (g:mL), while the temperatures of crystallisation were varied from $-20^{\circ} \mathrm{C}-5^{\circ} \mathrm{C}$. Crystallisation time was also varied from $4 \mathrm{~h}$ to $30 \mathrm{~h}$ as shown in Table 1. We observed that the temperature at which the PFAM were solubilised before crystallisation to be at room temperature $\left(25-35^{\circ} \mathrm{C}\right)$ with strong stirring in the case of low concentration. However, the temperature was increased to $\left(55^{\circ} \mathrm{C}\right)$ in the case of high concentration of PFAM to make the mixture homogenous and completely dissolved. Then the mixture was allowed to cool progressively to specific temperature and time.

The mixture of liquid and crystals was filtered using the Buchner funnel under reduced pressure. The funnel was precooled to the same crystallisation temperature as the solvent and FFAs. The crystals were washed once on the filter with the proper amount of a pre-cooled methanol to the same crystallisation temperature of the chilled liquid and crystals. The solvent was evaporated from the solid and liquid fractions under reduced pressure. The same process was repeated one time with solid fraction, which means double crystallisation.

\section{5 lodine Value}

Iodine value (IV) of fatty acids before and after crystallisations was determined by using AOCS (Cd 1d-92, Wijs method) (AOCS, 2004; Japir et al., 2017). In brief, an appropriate amount of fatty acid sample was first placed into a $500 \mathrm{~mL}$ flask with $25 \mathrm{~mL}$ of the Wij's solution. Then, $15 \mathrm{~mL}$ of cyclohexane (oil solvent) was then added to the oil sample. Following this was storing the mixture in darkness for an hour at ambient temperature, and it was agitated periodically to attain stabilisation. $150 \mathrm{~mL}$ of distilled water and $20 \mathrm{~mL}$ of potassium iodide solution (KI 10\%) were then added to the mixture. The mixture was subsequently titrated against sodium thiosulphate $\left(0.1 \mathrm{~N} \mathrm{Na}_{2} \mathrm{~S}_{2} \mathrm{O}_{3}\right)$ until a yellow colour emerged. After that, $1 \mathrm{~mL}$ of starch $(1 \%)$ was added and the titration process was continued till the blue colour dissipated. The same process was replicated with a blank under the same conditions. Iodine value was determined using equation (2) illustrated as follows:

$\mathrm{IV}=\frac{\left.\left(\mathrm{V}_{\mathrm{b}}-\mathrm{V}_{\mathrm{s}}\right) \times(\mathrm{N}) \text { of titrant }\right) \times(12.69)}{\text { weight of samples in grammes }}\left(\frac{\mathrm{g} \mathrm{I}_{2}}{100 \mathrm{~g} \text { sample }}\right)$,

where, $\mathrm{N}$ is normality of $0.1 \mathrm{~N} \mathrm{Na} \mathrm{Na}_{2} \mathrm{~S}_{2} \mathrm{O}_{3}$ solution; $\mathrm{V}_{\mathrm{b}}$ is a volume of $0.1 \mathrm{~N} \mathrm{Na}_{2} \mathrm{~S}_{2} \mathrm{O}_{3}$ solution in $\mathrm{mL}$ used for titration of blank; $\mathrm{V}_{\mathrm{S}}$ is a volume of $0.1 \mathrm{~N} \mathrm{Na}_{2} \mathrm{~S}_{2} \mathrm{O}_{3}$ solution in $\mathrm{mL}$ used for titration of the sample; 12.69 is used to transfer of milliequivalent of $\mathrm{Na}_{2} \mathrm{~S}_{2} \mathrm{O}_{3}$ to gram iodine, relative molecular mass of iodine is $126.9 \mathrm{~g}$.

\subsection{Preparation of Fatty Acid Methyl Ester (FAME)}

Briefly, a reagent is a mixture of $10 \mathrm{~mL}$ methanol with $2.5 \mathrm{~mL}$ concentrated hydrochloric acid $(37 \%)$. The reaction
Table 1. Independent variables and their variable levels for separation of saturated fatty acids and selection of the optimal factor.

\begin{tabular}{lrrrr}
\hline Independent variables & \multicolumn{4}{c}{ Variable levels } \\
\hline & & -1 & 0 & 1 \\
Fas - to- MeOH ratio $(\mathrm{w} / \mathrm{v})\left(\mathrm{g} \mathrm{mL}^{-1}\right)$ & $X_{1}$ & 5 & 15 & 25 \\
Crystallisation temperature $\left({ }^{\circ} \mathrm{C}\right)$ & $X_{2}$ & -20 & -7.5 & 5 \\
Crystallisation time $(\mathrm{h})$ & $X_{3}$ & 4 & 17 & 30 \\
\hline
\end{tabular}

Table 2. The yield\% of palm fatty acid mixture and ffas determination after hydrolysis high free fatty acid crude palm oil.

\begin{tabular}{llllr}
\hline Run & Oil sample weight & FFAs weight & Yield (\%) & \%FFAs \\
\hline 1 & 25 & 22 & 88 & 100.4 \\
2 & 25 & 22.15 & 88.6 & 99.3 \\
3 & 25 & 22.25 & 89.0 & 98.3 \\
\hline
\end{tabular}

was done in a $50 \mathrm{~mL}$ two-neck round-bottom flask at $65^{\circ} \mathrm{C}$, and it was provided with a standard taper joint (19/38) and short condenser. Then, $2 \mathrm{~g}$ of fatty acids and $7.5 \mathrm{~mL}$ methanol were added with $1.5 \mathrm{~mL}$ of the previous reagent and followed by $1.5 \mathrm{~mL}$ of toluene and the mixture was heated at $65^{\circ} \mathrm{C}$ for $1.5 \mathrm{~h}$. Next, the mixture was transferred to a separatory funnel. After that, $10 \mathrm{~mL}$ of hexane and $10 \mathrm{~mL}$ of distilled water were added. The mixture was allowed to stand till there were completely two layers. Then, the upper layer was collected and dried overnight over anhydrous sodium sulphate. Finally, $1 \mu \mathrm{L}$ was injected manually into a GC-FID (Japir et al., 2016a).

\subsection{GC-FID analyses}

Gas chromatography analyses were performed using gas chromatograph (Model 5890 SERIES II GC, HEWLETT PACKARD, USA) software equipped with a flame ionisation detector (FID) and a BPX-70 fused silica capillary column ( $30 \mathrm{~m}, 0.25 \mathrm{~mm}$ i.d., $0.25-\mu \mathrm{m}$ film thickness). The injector was maintained at $280^{\circ} \mathrm{C}$. Operating conditions were as follows: helium as the carrier gas was at a flow rate of $1 \mathrm{~mL} \mathrm{~min}^{-1}$, injection volume $1 \mu \mathrm{L}$ and a split ratio of $60: 1$. The oven temperature was maintained at $120^{\circ} \mathrm{C}$ and increased to $245^{\circ} \mathrm{C}$ and hold for $15 \mathrm{~min}$ at a rate of $3{ }^{\circ} \mathrm{C}$ per minute for $56.6 \mathrm{~min}$ of analysis. The FAME peaks were classified and quantified by comparing their peak areas and retention times with that of the pure standard FAME (Japir et al., 2016b).

\section{Results and discussion}

\subsection{Recovering FFAs after hydrolysis and FFAs determination}

High free fatty acid crude palm oil was hydrolysed to yield of PFAM and glycerol as a side product. The yield of PFAM and its palmitic acid percentage for 3 runs are outlined in Table 2. The average yield $\%$ and $\%$ FFAs are $88.5 \pm 0.5 \%$ and $99.3 \pm 1.1 \%$, respectively. A high percentage of FFA of PFAM 
refers to completely hydrolysed of HFFA-CPO into PFAM. The main product is $P F A M$ with high percentage yield, the remaining percentage of yield refers to glycerol as side product, which could be used in several oleochemical industries.

\subsection{Variation in fatty acid composition of HFFA-CPO and palm fatty acids mixture}

The fatty acid composition of HFF-CPO and PFAM subjected to base and acid catalysed preparation comprise palmitic $(44.4 \%, 42.3 \%)$, oleic $(39.8 \%, 42.1 \%)$, and linoleic acid $(10.0 \%, 9.9 \%)$, stearic $(4.4 \%, 4.3 \%)$, myristic $(1.1 \%$, $1.0 \%)$, lauric $(0.3 \%, 0.2 \%)$, linolenic acid $(0.0 \%, 0.2 \%)$, respectively, as shown in Table 3 . The fatty acid compositions of HFFA-CPO and PFAM are relatively different because of the fatty acid in HFFA-CPO, which only refers to oil composition. However, fatty acids composition in PFAM represents fatty acids and FFAs composition due to the hydrolysis process.

\subsection{Separation of saturated fatty acids}

The separation of PFAM by crystallisation from methanol basically depends on the solubility differences between the various components of the mixture of fatty acids. Since higher

Table 3. Fatty acid composition (\%) of palm fatty acid mixture after hydrolysis and high free fatty acid crude palm oil.

\begin{tabular}{|c|c|c|}
\hline Fatty acids composition & HFFACPO $(\%)^{*}$ & PFAM (\%) \\
\hline Lauric acid $_{(\mathrm{C} 12: 0)}$ & 0.3 & 0.2 \\
\hline Myristic acid $_{(\mathrm{C} 14: 0)}$ & 1.1 & 1.0 \\
\hline Palmitic acid ${ }_{(\mathrm{C} 16: 0)}$ & 44.4 & 42.3 \\
\hline Stearic acid ${ }_{(\mathrm{C} 18: 0)}$ & 4.4 & 4.3 \\
\hline$\sum$ SFAs & 50.2 & 47.8 \\
\hline Oleic acid $(\mathrm{C} 18: 1)$ & 39.8 & 42.1 \\
\hline Linoleic acid $_{(\mathrm{C} 18: 2)}$ & 10.0 & 9.9 \\
\hline Linolenic acid (C18:3) & - & 0.2 \\
\hline$\sum$ USFAs & 49.8 & 52.2 \\
\hline
\end{tabular}

saturated fatty acids are much less soluble than the corresponding unsaturated fatty acids, the advantage has often been taken of this fact to partially separate mixtures as shown in Table 4. As a fatty acid, long chain saturated fatty acids, such as stearic acid and palmitic acid, are a relatively nonpolar compound. However, short chain saturated fatty acids, such as lauric acid and myristic acid, exhibit more polarity compared to stearic and palmitic acids. Concerning monosaturated fatty acids and polyunsaturated fatty acids, they are characterized to be more polar than saturated fatty acids. The solubility of palm fatty acids mixture in methanol in the order of increased polarity is linolenic acid, linoleic acid, oleic acid, lauric acid, myristic acid, palmitic acid, and stearic acid. Therefore, based on the principle that "like dissolve like", unsaturated fatty acids will be more soluble than saturated fatty acids in methanol. The solubility behaviour of PFAM in methanol at a specified temperature was also explained based on the polarity and hydrogen bonding properties of the mixture components.

As a result, the separation is due to the high solubility of oleic acid, linoleic, and linolenic in methanol. However, SFAs, particularly palmitic acid is poorly soluble in methanol and is thus preferentially crystallised out. The slight increase in stearic acid is due to co-crystallization, given the solubility of other acids in PFAM. Lauric and myristic acids are saturated acids, but their concentrations are very low and their solubilities exceed that of palmitic acid. Consequently, they were soluble in methanol, thus leaving the sample enriched with palmitic acid (Dugan et al., 2017). In addition, it was suggested that the addition of water $3-5 \%$ to solvent, which greatly increases the solubility of USFAs without increasing that of the solubilities of palmitic and stearic acids (Uksila and Lehtinen, 1966).

The melting point of the FA changes with the number of carbons and the degree of unsaturation, thereby separating of the mixture of fatty acids into saturated and unsaturated fatty acids is probable (Wood et al., 2004). The solubility of fatty acids increases with the increase in temperature, and it is mainly reflected by their melting points: high melting point fatty acids are less soluble than low melting point fatty acids. For example, in C18 fatty acid series, stearic acid (18:0) melts at $70.1{ }^{\circ} \mathrm{C}$, oleic acid $(18: 1)$ at $16.3{ }^{\circ} \mathrm{C}$, linoleic $(18: 2)$ at $-6.5^{\circ} \mathrm{C}$ and linolenic $(18: 3)$ at $-12.8^{\circ} \mathrm{C}$ as shown in Table 5 .

Table 4. Solubility of fatty acids (g acid/100-g solution) in methanol at different temperatures.

\begin{tabular}{|c|c|c|c|c|c|c|c|}
\hline Temp $\left({ }^{\circ} \mathrm{C}\right)^{*}$ & \multicolumn{7}{|c|}{ Solubility } \\
\hline 10 & - & - & 1.310 & 0.259 & - & - & - \\
\hline-10 & 2.83 & 0.826 & 0.146 & 0.032 & - & - & - \\
\hline-20 & 1.70 & 0.344 & 0.063 & 0.010 & $4.02^{* *}$ & - & - \\
\hline-30 & 0.823 & 0.153 & 0.020 & - & 0.708 & - & - \\
\hline-50 & - & - & - & - & 0.089 & 2.52 & - \\
\hline-60 & - & - & - & - & 0.052 & 0.925 & - \\
\hline-62 & - & - & - & - & - & - & 1.76 \\
\hline-70 & - & - & - & - & 0.032 & 0.394 & - \\
\hline
\end{tabular}

\footnotetext{
* Temperature: Foreman and Brown (1944).

*** Brown and Kolb (1955).
} 
Table 5. Palm fatty acids melting point.

\begin{tabular}{llllllll}
\hline & \multicolumn{5}{c}{ Fatty acids } \\
\cline { 2 - 7 } & Lauric acid & Myristic acid & Palmitic acid & Stearic acid & Oleic acid & Linoleic acid & Linolenic acid \\
\hline Melting point $\left({ }^{\circ} \mathrm{C}\right)$ & 44.8 & 54.4 & 62.9 & 70.1 & 16.3 & -6.5 & -12.8 \\
\hline
\end{tabular}

Source: Cermak et al., (2012).

Consequently, an increase of the unsaturated fatty acid in the mixture usually leads to decreasing the melting point of the mixture while increasing the solubility of unsaturated fatty acid in methanol.

In order to improve the purity of palmitic acid in saturated fraction and oleic acid in unsaturated fraction, molecular distillation could be applied to purify SFAs fraction to form 99.9\% palmitic acid, and purify USFAs fraction to form $99.9 \%$ oleic acid due to higher percentage of these fatty acids in PFAM. Yet, molecular distillation cannot be applied to separate PFAM due to closeness of their boiling points (Japir et al., 2016a). However, molecular distillation could be applied to purify palmitic acid after separating lauric, myristic, oleic, linoleic and linolenic acids from the mixture using methanol crystallization and to produce palmitic acid $90 \%$. To this end, molecular distillation or preparative high performance liquid chromatography could also be applied to purify palmitic acid and produce $99.9 \%$ (Dugan et al., 2017). In this study, the percentage of palmitic acid that was obtained in the product could be sold commercially because some companies sale palmitic acid with $95 \%$.

The main aim of this current study is to determine the optimal conditions for efficiently separating the total SFAs as well as to obtain high purity palmitic acid $(90 \%)$ as a major component from PFAM. However, at the cold temperature behaviour, PFAM contained the minimum content of USFAs. As a result, further experiments were performed with solvent crystallisation under different ratios of fatty acids-to-solvent (w/v) as shown in Figure 1. Optimal crystallisation temperature and crystallisation time were achieved at $-15^{\circ} \mathrm{C}$, and $24 \mathrm{~h}$, respectively, with fatty acids-to-methanol ratio of $1: 15\left(\mathrm{~g} \mathrm{~mL}^{-1}\right)$. It can be observed in Figure 1 that there is a relationship between solvent volume, yield, and percentage of SFAs and palmitic acid, wherein the yield of SFAs decreased, and the percentage of SFAs and palmitic acid increased with the increase in the volume of solvent from 1:5 $\left(\mathrm{g} \mathrm{mL}^{-1}\right)-1: 25\left(\mathrm{~g} \mathrm{~mL}^{-1}\right)$. In all cases, increasing the amount of solvent from 1:5 to $1: 25(\mathrm{w} / \mathrm{v})$ led to lower yields and higher purity of SFAs and palmitic acid with a lower content of USFAs. If the concentration of fatty acid in a solvent is too high, then the precipitate tends to form a slimy mass which cannot be handled or washed except in small quantities under laboratory conditions (Muckerheide and Myers, 1947). In this study, the ratio of fatty acids-to-methanol was varied from $1: 5$ to $1: 25$.

The saturated fatty acids started to crystallise with the decrease of the mixture temperature. More crystals were observed when the temperature reached at $5^{\circ} \mathrm{C}$, for this reason, we have selected this temperature to be the higher one in the range of crystallisation temperature. The higher temperature $5^{\circ} \mathrm{C}$ in the case of the $1: 15\left(\mathrm{~g} \mathrm{~mL}^{-1}\right)$ ratio and $24 \mathrm{~h}$ led to a slightly higher yield of precipitate mass, as shown in Figure 2.

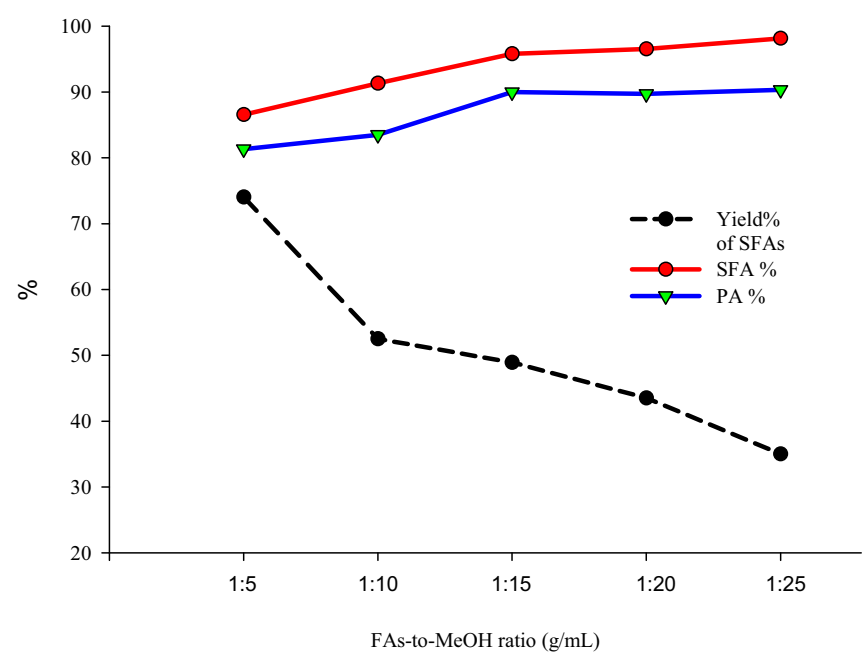

Fig. 1. Effect of FAs-to- solvent ratio (w/v) of fractionation of FAs at $-15^{\circ} \mathrm{C}$ and $24 \mathrm{~h}$.

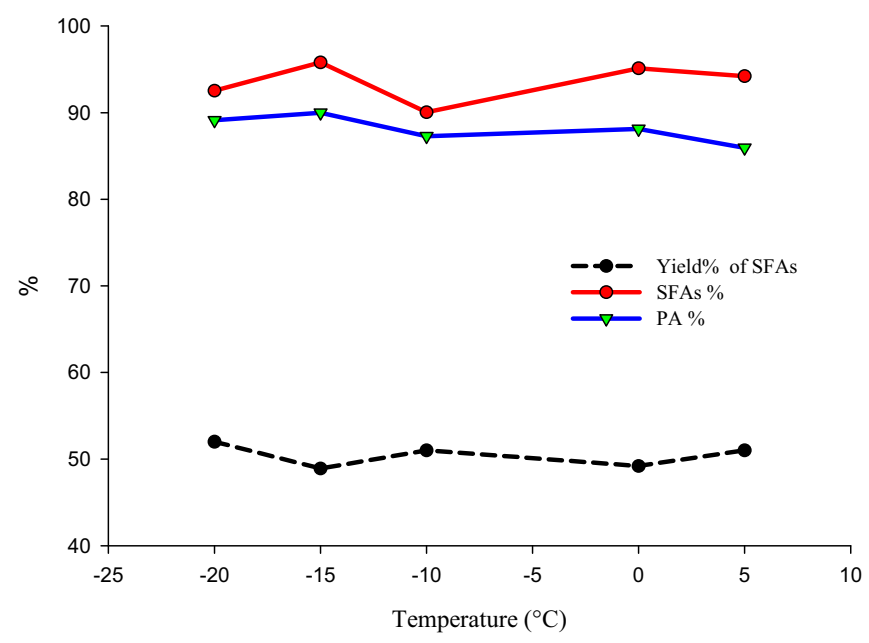

Fig. 2. Effect of crystallisation temperature of fractionation of PFAM using methanol with a ratio $1: 15(\mathrm{w} / \mathrm{v})$ at $24 \mathrm{~h}$.

Based on the theoretical concept, it was better to do the crystallisation in progressive cooling, which results in better washing of the filter cake and which is more pure and easy to further process such as washing and drying. However, we do not have the technique in our lab and we strongly suggest achieving it in future studies.

However, the amount of USFAs in the precipitate was slightly higher compared to other experiments. Although the 
low temperature of $-15^{\circ} \mathrm{C}$ and $1: 15$ ratio and $24 \mathrm{~h}$ led to a higher yield of precipitate mass, the amount of USFAs in the precipitate was lower. Consequently, for further experiments, the selected optimum conditions comprise methanol solvent, temperature of $-15^{\circ} \mathrm{C}$, solvent ratio of $1: 15$ and time of $24 \mathrm{~h}$.

The next step involves optimisation of the crystallisation time required for fractionation. Figure 3 shows the results of fractionation experiments using 95\% methanol at a ratio $1: 15$ (g: $\mathrm{mL}$ ) and $-15^{\circ} \mathrm{C}$ with crystallisation times of $4 \mathrm{~h}, 10 \mathrm{~h}, 16 \mathrm{~h}$, $24 \mathrm{~h}$, and $30 \mathrm{~h}$. The yields of the precipitates showed a slight difference, although a larger difference is observed for unsaturated fatty acids. After $4 \mathrm{~h}$ of crystallisation, the fraction of unsaturated fatty acids in the precipitates remained low because the temperature only reached $-15^{\circ} \mathrm{C}$ at $4 \mathrm{~h}$. After $10 \mathrm{~h}$, the amount of USFAs in the precipitate remained relatively constant with no significant improvement. However, the precipitate at a crystallisation time of $24 \mathrm{~h}$ exhibited the highest content of SFAs. Therefore, the crystallisation time of $24 \mathrm{~h}$ was selected for further experiments. Moreover, prolonging the crystallisation time $(30 \mathrm{~h})$ did not improve the results as shown in Figure 3. The solution temperature has to be decreased to a specific crystallisation temperature slowly (1-6h) and needs to be maintained there for 4-24h (Wanasundara et al., 2005).

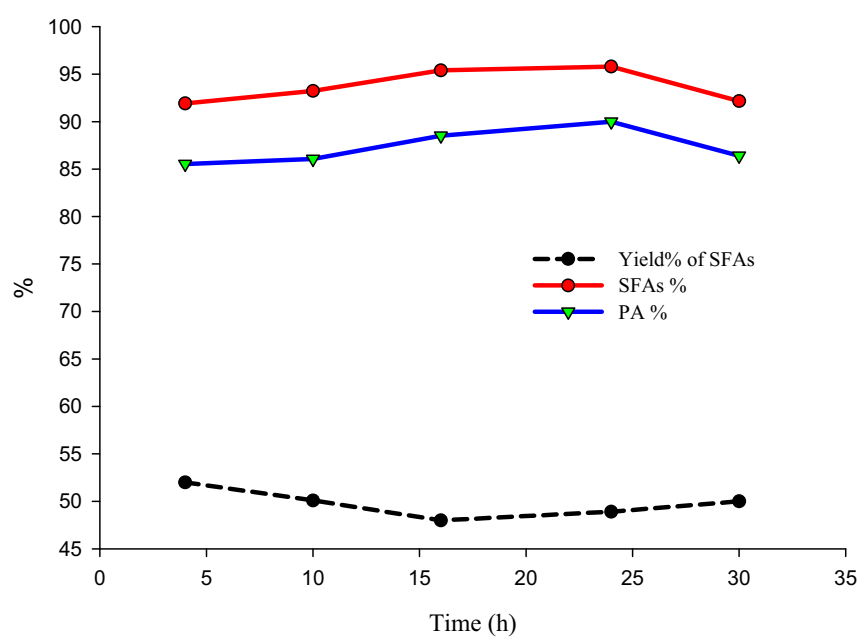

Fig. 3. Effect crystallisation time of fractionation of FAs using methanol with a ratio of $1: 15(\mathrm{w} / \mathrm{v})$ at $-15^{\circ} \mathrm{C}$.

\subsection{Repeat experiment (Verification test)}

A verification test was performed at conditions that include methanol: fatty acids ratio of $15: 1$ ( $\mathrm{g}: \mathrm{mL})$, crystallisation temperature of $-15^{\circ} \mathrm{C}$, and reaction time of 24 hours. The results in Table 6 show that more than $48.7 \%$ of SFAs with over $89.3 \%$ recovery was obtained from PFAM at the optimised methanol crystallisation conditions.

\subsection{Saturated fatty acids composition}

The fatty acids composition was conducted after transesterification using the GC-FID analysis. The composition of fatty acids before and after crystallisation is also shown in Figure 4 and Table 7. It is observed that there are highly significant differences between the composition of fatty acids in PFAM, and SFAs in the solid fraction after methanol crystallisation. The composition of fatty acids in PFAM comprises $0.2 \%$ of lauric acid (C12:0), 1.0\% of myristic acid (C14:0), $42.3 \%$ of palmitic acid (C16:0), 4.3\% of stearic acid (C18:0), 42.1\% of oleic acid (C18:1), 9.9\% of linoleic acid $(\mathrm{C} 18: 2)$ and $0.2 \%$ of linolenic acid (C18:3). However, the composition of SFAs after first crystallisation at optimum conditions consists of $0.5 \%$ of myristic acid (C14:0), $68.3 \%$ of palmitic acid (C16:0), 7.0\% of stearic acid (C18:0), 20.2\% of

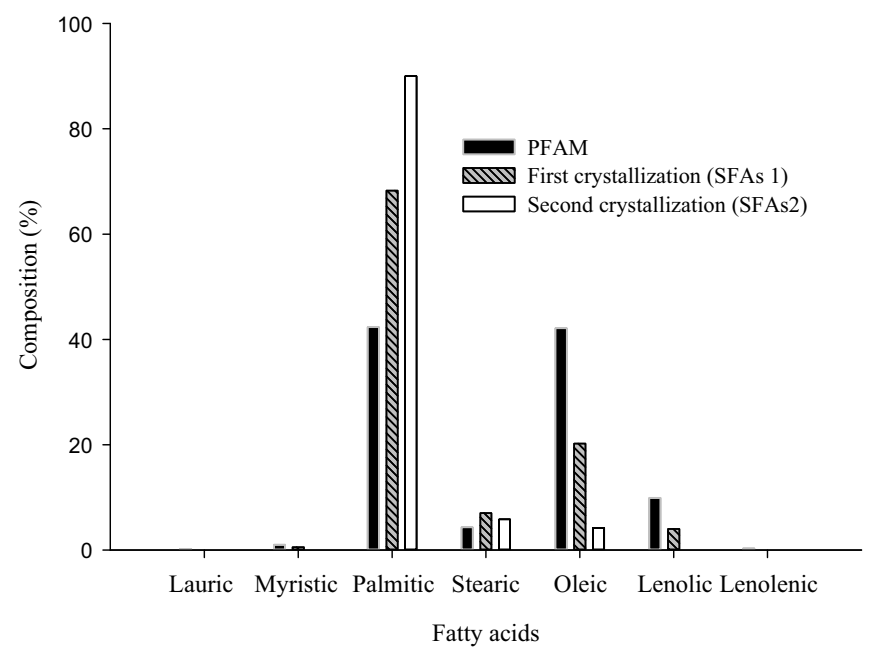

Fig. 4. Fatty acids profile of PFAM and SFAs before and after methanol crystallisation.

Table 6. Verification test results.

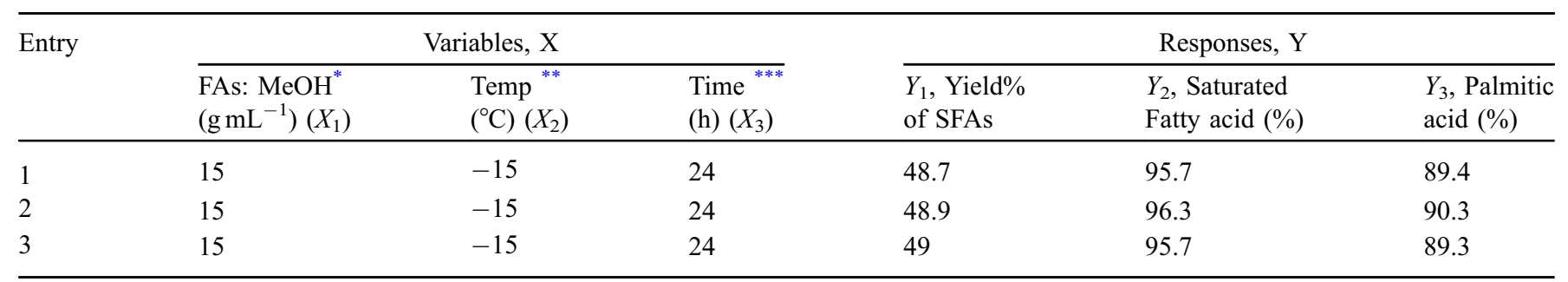

\footnotetext{
${ }^{*}$ Fatty acids: methanol ratio.

** Crystallisation temperature.

${ }^{* * *}$ Crystallisation time.
} 
Table 7. Fatty acids composition (\%) of palm fatty acids mixture (pfam) before solvent crystallisation and saturated fatty acid (sfas) after methanol crystallisation at optimal conditions.

\begin{tabular}{lllllllllll}
\hline Operation & $\begin{array}{l}\text { Lauric } \\
\text { acid }\end{array}$ & $\begin{array}{l}\text { Myristic } \\
\text { acid }\end{array}$ & $\begin{array}{l}\text { Palmitic } \\
\text { acid }\end{array}$ & $\begin{array}{l}\text { Stearic } \\
\text { acid }\end{array}$ & $\sum$ SFA & $\begin{array}{l}\text { Yield of } \\
\text { SFAs \% }\end{array}$ & $\begin{array}{l}\text { Oleic } \\
\text { acid }\end{array}$ & $\begin{array}{l}\text { Linoleic } \\
\text { acid }\end{array}$ & $\begin{array}{l}\text { Linolenic } \\
\text { acid }\end{array}$ & $\begin{array}{l}\sum \text { USFA } \\
\text { USFAs \% }\end{array}$ \\
\hline PFAM & 0.2 & 1.0 & 42.3 & 4.3 & 47.8 & - & 42.1 & 9.9 & 0.2 & 52.2 \\
SFAs1 & - & 0.5 & 68.3 & 7.0 & 75.8 & 53.6 & 20.2 & 4.0 & - & 24.2 \\
SFAs2 & - & - & 90 & 5.8 & 95.8 & 48.9 & 4.2 & - & - & 4.2 \\
\hline
\end{tabular}

SFAs: saturated fatty acids; USFAs: unsaturated fatty acids; PFAM: palm fatty acids mixture; SFAs1: first crystallisation; SFAs2: second crystallisation.

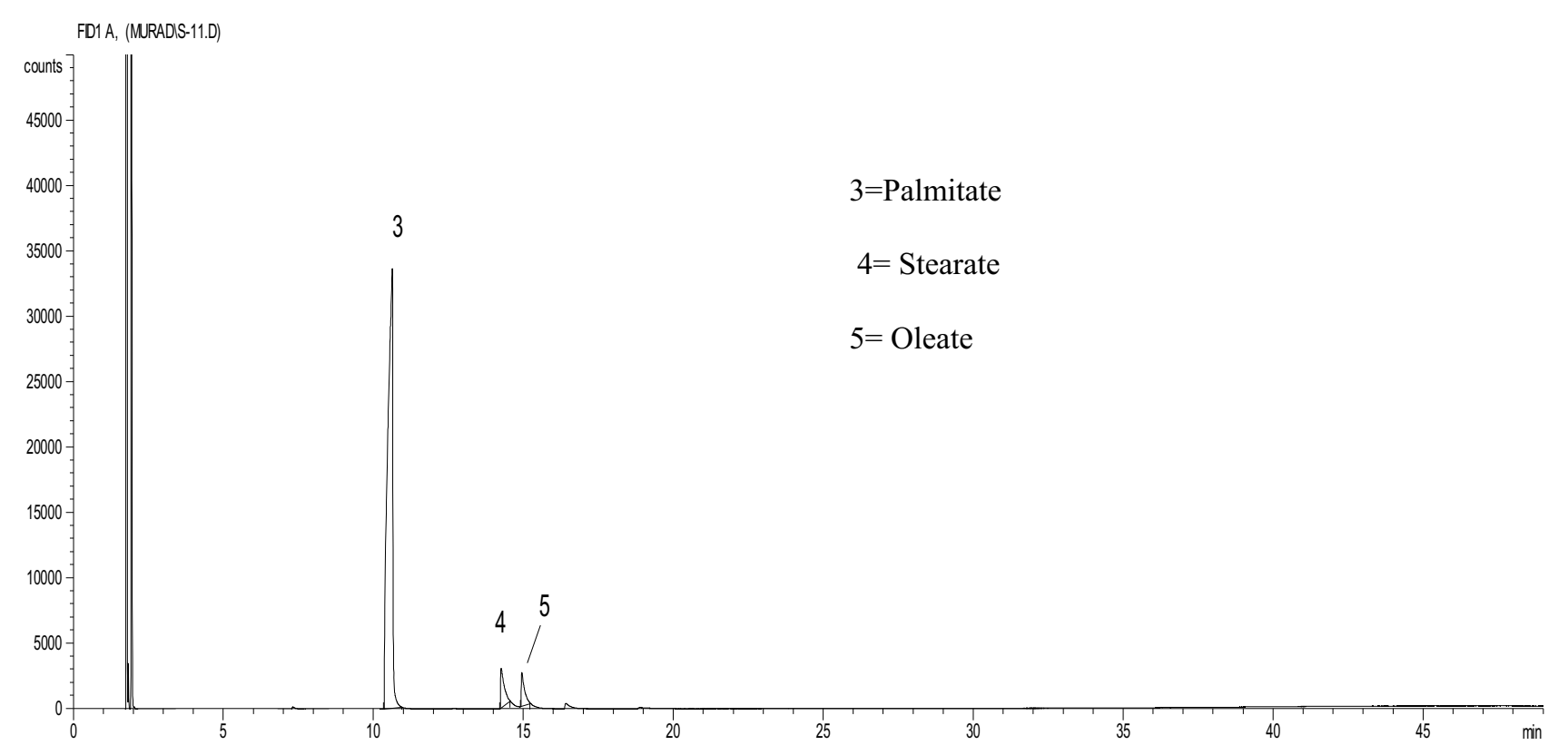

Fig. 5. GC chromatogram of FAs composition in SFAs after second methanol crystallisation.

oleic acid (C18:1) and 4.0\% of linoleic acid (C18:2) as shown in Table 7. After the second methanol crystallisation, the separated SFAs composition in the solid fraction contains $90 \%$ of palmitic acid (C16:0), 5.8\% of stearic acid (C18:0), and $4.2 \%$ of oleic acid (C18:1). The maximum SFAs purity of $95.8 \%$ was achieved. It was shown that stearic acid (C18:0) increased from $4.3 \%$ to $5.8 \%$, as shown in Table 7 and Figure 5. The monounsaturated fatty acids (MUSFA), oleic acid (C18:1), decreased from $42.1 \%$ to $4.2 \%$. As observed, there are no peaks for polyunsaturated fatty acids (PUSFAs), linoleic acid (C18:2), linolenic acid (C18:3) as well as SFAs, lauric acid (C12:0) and myristic acid (C14:0). This indicates that methanol crystallisation is an efficient technique for separating SFAs concentrates from PFAM by hydrolyzing the product of high free fatty acid crude palm oil because of differences in the PFAM solubilities.

\section{6 lodine value}

The iodine value indicates the level of unsaturation in the sample. The iodine value of SFAs after the second crystallisation was $5.7 \mathrm{~g} / 100 \mathrm{~g}$, which is lower than the iodine value of SFAs after first crystallisation and lower than PFAM before crystallisation. It can be seen that iodine value

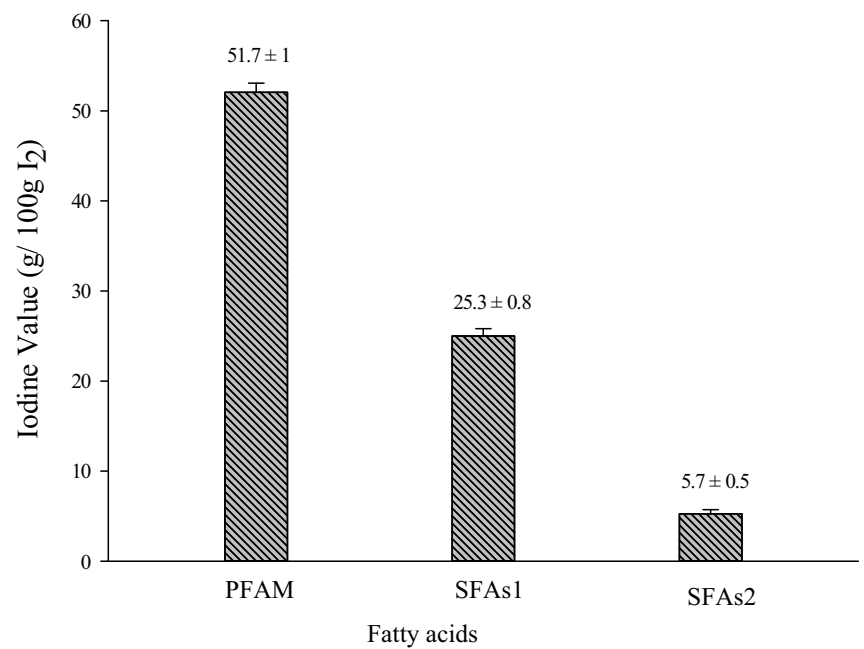

Fig. 6. The iodine value of palm fatty acids mixture and saturated fatty acids before and after methanol crystallisation.

decreased gradually with repeated crystallisation due to the decreased concentration of USFAs in the solid fraction after methanol crystallisation, as shown in Figure 6. 


\section{Conclusion}

Saturated fatty acids were successfully separated using a highly efficient method and the final product consisted of palmitic acid as a major component. The fatty acids-to-methanol ratio (w/ v) had a highly significant influence on the yield and the percentage of SFAs. However, crystallisation temperature and crystallisation time had a significant influence on the yield and the percentage of SFAs. The maximum percentage of SFAs was over $95 \%$ when including palmitic acid over $89 \%$ as a major component. The ratio of yield was up to $48.9 \%$ under the optimal conditions at FAs-to-MeOH of 1:15 (w/v), and the crystallisation temperature was $-15^{\circ} \mathrm{C}$, while the crystallisation time was $24 \mathrm{~h}$. The components of separated SFAs from high free fatty acid crude palm oil are $90 \%$ of palmitic acid (C16:0), 5.8\% of stearic acid (C18:0). Only $4.2 \%$ of oleic acid (C18:1) was characterised in the product. However, lauric, myristic and linoleic acids were not observed in the final solid product. More details for the kinetic studies and getting high percentage still need to be studied in future using combined molecular distillation and solvent-assisted crystallization. In conclusion, methanol crystallisation is a promising method to obtain high palmitic acid concentrates as a major component in SFAs in a solid fraction from high free fatty acid crude palm oil. It has a potential value of large-scale production of SFAs. In addition, the used methanol (95\%) in this study could be recycled to support the principle of green chemistry. This method could be one of the most efficient, cheap and simple methods that could be applied in the separation of fatty acids mixture.

Acknowledgments. The authors appreciatively acknowledge the support of Universiti Kebangsaan Malaysia for the financial and technical support during carrying out this research. Our thankfulness should also be dedicated to the Advanced Medical and Dental Institute (AMDI), Universiti Sains Malaysia (USM), and Ministry of Science, Technology and Innovation (MOSTI) of Malaysia, which funded this project via grant \# FRGS/2/2014/ST01/UKM/01/2, GUP/ 2016/063 and Sime Darby Sdn Bhd via grant \# ST-2014-019.

\section{References}

AOCS. 1990. Method Ca 5a-40. Estimation of free fatty acid value. Official methods and recommended practices of the American oil Chemists Society, 5th ed., Firestone D, ed. Champaign, IL, USA: AOCS.

AOCS. 2004. Method Cd 1d-92. Estimation of iodine value (Wij's method). Official methods and recommended practices of the American oil Chemists Society, 5th ed., Firestone D, ed. Champaign, IL, USA: AOCS.

Brown J, Kolb DK. 1955. Applications of low temperature crystallization in the separation of the fatty acids and their compounds. Prog Chem Fats Other Lipids 3: 57-94.

Cermak SC, Kenar JA, Evangelista RL. 2012. Distillation of natural fatty acids and their chemical derivatives. London (United Kingdom): INTECH Open Access Publisher.
Dogan TH, Temur H. 2013. Effect of fractional winterization of beef tallow biodiesel on the cold flow properties and viscosity. Fuel 108: 793-796.

Dugan ME, Gzyl KE, Rolland DC, Vahmani P. 2017. Combined short-path distillation and solvent-assisted crystallization of beef Fatty Acid Methyl Esters. J Am Oil Chem Soc 94: 1503-1508.

Foreman HD, Brown J. 1944. Solubilities of the fatty acids in organic solvents at low temperatures. Oil Soap 21: 183-187.

Japir AAW, Salimon J, Derawi D, Bahadi M, Yusop MR. 2016a. Purification of high free fatty acid crude palm oil using molecular distillation. Asian J Chem 28: 2549-2554.

Japir AAW, Salimon J, Derawi D, Bahadi M, Yusop MR. 2016b. Separation of free fatty acids from high free fatty acid crude palm oil using short-path distillation. In: The 2016 UKM FST postgraduate colloquium: Proceedings of the Universiti Kebangsaan Malaysia, Faculty of Science and Technology 2016 Postgraduate Colloquium (Vol. 1784, $\mathrm{N}^{\circ}$ 1, p. 030001). AIP Publishing, 2016b. DOI: 10.1063/1.4966739.

Japir AAW, Salimon J, Derawi D, Bahadi M, Al-Shuja'a, S, Yusop MR. 2017. Physicochemical characteristics of high free fatty acid crude palm oil. $O C L$ 24: 1-9.

Kempers P, Schörken U, Wolf T et al. 2013. Process for production of fatty acids, fatty acid esters and sterolesters from soapstock, Google Patents.

Kistler R, Muckerheide V, Myers L. 1946. The commercial solvent separation of fatty acids. J Am Oil Chem Soc 23: 146-150.

Kostik V, Memeti S, Bauer B. 2013. Fatty acid composition of edible oils and fats. J Hyg Eng Des 4: 112-116.

Maddikeri GL, Pandit AB, Gogate PR. 2012. Adsorptive removal of saturated and unsaturated fatty acids using ion-exchange resins. Ind Eng Chem Res 51: 6869-6876.

Muckerheide VJ, Myers LD 1947. Method of separating fatty acids, Google Patents.

Prasanth Kumar P, Gopala Krishna A. 2015. Physicochemical characteristics of commercial coconut oils produced in India. Grasas y Aceites 66: e062.

Salimon J, Abdullah BM, Salih N. 2011. Hydrolysis optimization and characterization study of preparing fatty acids from Jatropha Curcas seed oil. Chem Cent J 5: 1-9.

Salimon J, Abdullah BM, Salih N. 2012. Selectively increasing of polyunsaturated (18:2) and monounsaturated (18:1) fatty acids in Jatropha Curcas seed oil by crystallization using D-optimal design. Chem Cent J 6: 1-15.

Strohmeier K, Schober S, Mittelbach M. 2014. Solvent-assisted crystallization of fatty acid alkyl esters from animal fat. $\mathrm{J} \mathrm{Am} \mathrm{Oil}$ Chem Soc 91: 1217-1224.

Uksila E, Lehtinen I. 1966. Crystallization of linseed oil fatty acids from acetonitrile. Acta Chem Scand :20.

Wanasundara U. 2010. Preparative and industrial + scale isolation and purification of omega +3 polyunsaturated fatty acids from marine sources. Handbook of seafood quality, safety and health applications. Ames (Oxford): Blackwell Publishing Ltd.

Wanasundara UN, Wanasundara P, Shahidi F. 2005. Novel separation techniques for isolation and purification of fatty acids and oil by+products. Bailey's Industrial Oil and Fat Products, 6th ed. New York (USA): Wiley.

Wood J, Richardson R, Nute G, et al. 2004. Effects of fatty acids on meat quality: a review. Meat Sci 66: 21-32.

Cite this article as: Japir AA-W, Salimon J, Derawi D, Yahaya BH, Bahadi M, Al-Shuja'a S, Yusop MR. 2018. A highly efficient separation and physicochemical characteristics of saturated fatty acids from crude palm oil fatty acids mixture using methanol crystallisation method. OCL 25(2): A203. 